\title{
Early Systolic Blood Pressure Changes in Incident Hemodialysis Patients Are Associated with Mortality in the First Year
}

\author{
Murat H. Sipahioglua, ${ }^{a, b}$ Len Usvyat ${ }^{b}$ Li Liu $^{b, d}$ Samer R. Abbas ${ }^{b}$ \\ Jochen G. Raimann ${ }^{b}$ Laura Rosales ${ }^{b}$ Nathan W. Levin ${ }^{b}$ Peter Kotankob, c \\ a Department of Nephrology, Medical Faculty, Erciyes University, Kayseri, Turkey; ${ }^{b}$ Renal Research Institute, \\ and ${ }^{\mathrm{C} B e t h}$ Israel Medical Center, New York, N.Y., USA; ${ }^{\mathrm{d} I n s t i t u t e}$ and Division of Nephrology, Peking University \\ First Hospital, Beijing, China
}

\section{Key Words}

Hemodialysis $\cdot$ Mortality $\cdot$ Systolic blood pressure

\begin{abstract}
Background: In incident hemodialysis (HD) patients, the relationship between early systolic blood pressure (SBP) dynamics and mortality is unknown. Methods: Baseline SBP levels were stratified into 5 categories ranging from $<120$ and $\geq 180 \mathrm{~mm} \mathrm{Hg}$. Early pre-HD SBP change was defined as the slope of pre-HD SBP from week 1 to 12 and categorized in quartiles (Q1, lowest slope). SBP slopes were computed for each patient by simple linear regression. Results: In 3,446 incident HD patients ( $42 \%$ females, $44 \%$ black, age $62 \pm 15$ years), the median pre-HD SBP slope was -1.7 (Q1) to +2.3 (Q4) $\mathrm{mm} \mathrm{Hg} /$ week. In an adjusted multivariate Cox regression analysis, patients with declining SBP (slope Q1) had higher mortality compared to patients with increasing preHD SBP (slope Q4) at 12 months (hazard ratio $2.01,95 \%$ confidence interval 1.35-3.01). In addition, patients with baseline pre-HD SBP $<120 \mathrm{~mm} \mathrm{Hg}$ showed higher mortality compared to the reference group (SBP $\geq 180 \mathrm{~mm} \mathrm{Hg}$ ) at 12 months (hazard ratio 1.89, 95\% confidence interval 1.033.45). Conclusion: Baseline pre-HD SBP and early SBP dynamics are associated with mortality in the first year of dialy-
\end{abstract}

sis. Patients who had low (pre-HD SBP $<120 \mathrm{~mm} \mathrm{Hg}$ ) or declining SBP had the highest mortality rates. Particular attention is warranted in incident HD patients with low or declining SBP.

Copyright ๑ 2012 S. Karger AG, Basel

\section{Introduction}

Renal regulation of body fluid volume and of blood pressure (BP) is impaired in patients with chronic kidney disease (CKD), making hypertension (HTN) highly prevalent. HTN is present in approximately $80-85 \%$ of patients with CKD [1]. HTN plays a major role in development of left ventricular hypertrophy, congestive heart failure, coronary artery disease and cerebrovascular disease and results in increased cardiovascular morbidity and mortality [2]. The majority of CKD patients are hypertensive prior to the start of dialysis. However, hemodialysis (HD) does not result in an appreciably lower frequency of HTN, and a prevalence of up to $80 \%$ is reported [3]. In addition to pre-existing HTN, non-adherence to salt restriction, intradialytic sodium gain due to dialysate sodium concentration exceeding serum levels, inappropriate sodium profiling, and intradialytic adminis-

\section{KARGER}

Fax +4161306 1234 E-Mail karger@karger.ch www.karger.com

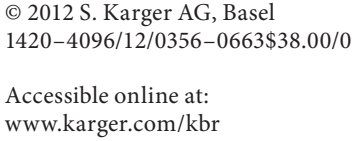

E-Mail pkotanko@ rriny.com 
tration of saline are associated with the high prevalence of HTN in HD patients. High BP may be further aggravated by increased sympathetic activity, the cause of which is multifactorial [4]. There is no generally accepted definition of HTN in HD patients [5]. In non-dialysis adults, HTN was defined by the Joint National Committee on Prevention, Detection, Evaluation and Treatment of High Blood Pressure (JNC VII) as systolic BP (SBP) $\geq 140 \mathrm{~mm} \mathrm{Hg}$ and/or diastolic BP $\geq 90 \mathrm{~mm} \mathrm{Hg}$ [6]. The National Kidney Foundation Kidney Disease Outcomes Quality Initiative recommended in-center predialysis BP targets for HD patients $<140 / 90 \mathrm{~mm} \mathrm{Hg}$ [7]. The evidence level for this recommendation is low since it was based on studies performed in pre-HD CKD patients. Survival analysis in $\mathrm{HD}$ patients revealed a U-shaped relationship between SBP and mortality with excess mortality risk in patients at the extremes, i.e. those in the lowest and highest strata of SBP [8-10] and those with declining SBP [11]. The impairment of left ventricular function by the effect of prior long-standing high SBP could explain to an extent the association between low SBP and mortality.

In the present study, we were particularly interested in SBP dynamics in the early time period after HD initiation. More specifically, we aimed to test the hypothesis that a low and/or declining SBP in the first 12 weeks on HD is related to increased mortality in the first year of treatment.

\section{Methods}

In this retrospective study, we investigated a large cohort of incident HD patients treated in Renal Research Institute facilities between 1 January 2001 and 30 July 2008. All incident patients $>18$ years and surviving beyond day 90 were included. All patients were followed until discharge from Renal Research Institute facilities, death or at the end of year 1 .

BP Measurement and BP Categories

$\mathrm{BP}$ was measured before each $\mathrm{HD}$ in the sitting position using the standard BP module (Colin Medical Technology, M2600; Japan) integrated in the HD machines.

Weekly pre-HD SBP was obtained by averaging the three preHD SBP values of any given week. Week 0 was defined as the week of in-center HD initiation. Baseline pre-HD SBP was defined as the average pre-HD SBP of weeks 1-3 of HD and was stratified into 5 categories: category $1, \mathrm{SBP}<120 \mathrm{~mm} \mathrm{Hg}$; category 2, $120 \leq$ $\mathrm{SBP}<140 \mathrm{~mm} \mathrm{Hg}$; category 3, $140 \leq \mathrm{SBP}<160 \mathrm{~mm}$ Hg; category $4,160 \leq \mathrm{SBP}<180 \mathrm{~mm} \mathrm{Hg}$; category $5, \mathrm{SBP} \geq 180 \mathrm{~mm} \mathrm{Hg}$.

Early pre-HD SBP change was defined as the slope of pre-HD SBP between weeks 1 and 12. SBP slopes (in $\mathrm{mm} \mathrm{Hg} /$ week) were computed for each patient by simple linear regression and categorized into quartiles $(\mathrm{Q})$, with Q1 as the lowest and Q4 as the highest slope. The analysis in categories of SBP and SBP slopes was prespecified and motivated by our a priori reasoning that differ-

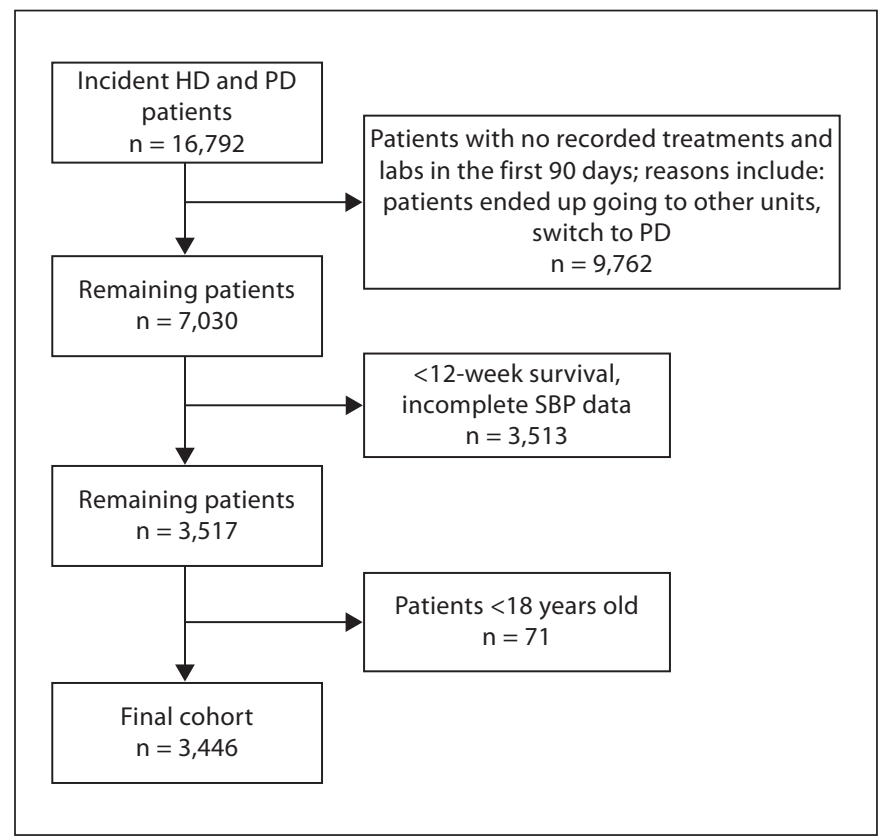

Fig. 1. Study flow diagram. $P D=$ Peritoneal dialysis.

ent slopes may be associated with outcomes in a non-linear fashion.

\section{Statistical Methods}

Data are expressed as the mean \pm standard deviation or as crude numbers and percentages. Continuous variables were compared between categories by analysis of variance, and categorical variables were compared by the $\chi^{2}$ test. Survival curves were calculated by the Kaplan-Meier method for SBP groups and SBP slope quartiles, and differences in survival times in the groups were compared by the log-rank test. The associations between the 5 categories of pre-HD SBP, quartiles of SBP slope and all-cause mortality at months 6 and 12 were evaluated with a Cox proportional hazards model. SBP category 5 (SBP $\geq 180 \mathrm{~mm} \mathrm{Hg}$ ) and SBP slope Q4 served as reference groups. Age at the start of $\mathrm{HD}$, sex, race (white/black/other), diabetic status, cardiovascular comorbidities (congestive heart failure, coronary artery disease, peripheral vascular disease), 12-week averages of laboratory values (serum albumin, creatinine, blood urea nitrogen, hemoglobin), interdialytic weight gain, dialysis adequacy (eKt/V) and normalized protein catabolic rate, as determined by formal urea kinetic modeling, were included as covariates in the Cox survival analyses.

\section{Results}

Of 16,792 screened incident HD patients, 3,446 comprised the final study cohort (fig. 1). In the final cohort, $42 \%$ were female, $44 \%$ were black, $47 \%$ were white, and the mean age was $62 \pm 15$ years. Diabetes mellitus was 
Table 1. Baseline characteristics

a Stratified per SBP groups $(\mathrm{n}=3,446)$

\begin{tabular}{|c|c|c|c|c|c|c|c|}
\hline & \multirow{2}{*}{$\begin{array}{l}\text { All patients } \\
(\mathrm{n}=3,446)\end{array}$} & \multicolumn{5}{|c|}{$\mathrm{SBP}, \mathrm{mm} \mathrm{Hg}$} & \multirow{2}{*}{$\begin{array}{l}\mathrm{p} \\
\text { value }\end{array}$} \\
\hline & & $\begin{array}{l}<120 \\
(\mathrm{n}=264)\end{array}$ & $\begin{array}{l}120-139.9 \\
(n=952)\end{array}$ & $\begin{array}{l}140-159.9 \\
(n=1,301)\end{array}$ & $\begin{array}{l}160-179.9 \\
(n=709)\end{array}$ & $\begin{array}{l}\geq 180 \\
(n=220)\end{array}$ & \\
\hline \multicolumn{8}{|l|}{ Age, years } \\
\hline Mean \pm SD & $61.5 \pm 15.1$ & $66.7 \pm 14.6$ & $63.1 \pm 16.0$ & $60.1 \pm 14.9$ & $60.4 \pm 14.3$ & $59.8 \pm 13.4$ & $<0.001$ \\
\hline Median & 62.5 & 69.8 & 64.6 & 60.8 & 61.2 & 60.8 & \\
\hline Range & $18.4-97.6$ & $20.6-90.2$ & $20.2-97.6$ & $18.4-94.4$ & $19.2-94.3$ & $22.3-89.1$ & \\
\hline Male & $2,000(58.0)$ & $173(65.5)$ & $585(61.4)$ & $765(58.8)$ & $381(53.7)$ & $96(43.6)$ & $<0.001$ \\
\hline Race & & & & & & & $<0.001$ \\
\hline Black & $1,504(43.6)$ & $84(31.8)$ & $384(40.3)$ & $578(44.4)$ & $355(50.1)$ & $103(46.8)$ & \\
\hline White & $1,635(47.4)$ & $165(62.5)$ & 494 (51.9) & $589(45.3)$ & $285(40.2)$ & $102(46.4)$ & \\
\hline Other & $307(8.9)$ & $15(5.7)$ & $74(7.8)$ & $134(10.3)$ & $69(9.7)$ & $15(6.8)$ & \\
\hline Body mass index & $27.6 \pm 7.1$ & $25.8 \pm 6.3$ & $27.3 \pm 6.8$ & $27.7 \pm 7.0$ & $27.9 \pm 7.3$ & $28.9 \pm 8.3$ & $<0.001$ \\
\hline Diabetes & $1,740(50.5)$ & 108 (40.9) & $384(40.3)$ & $679(52.2)$ & $408(57.5)$ & $161(73.2)$ & $<0.001$ \\
\hline \multicolumn{8}{|l|}{ Laboratory results } \\
\hline Albumin, g/dl & $3.6 \pm 0.4$ & $3.5 \pm 0.4$ & $3.6 \pm 0.5$ & $3.6 \pm 0.4$ & $3.5 \pm 0.4$ & $3.6 \pm 0.4$ & $<0.001$ \\
\hline Creatinine, mg/dl & $6.9 \pm 2.6$ & $5.4 \pm 1.8$ & $6.9 \pm 2.7$ & $7.2 \pm 2.7$ & $7.2 \pm 2.6$ & $7.1 \pm 2.5$ & $<0.001$ \\
\hline Hemoglobin, g/dl & $11.0 \pm 1.2$ & $10.9 \pm 1.1$ & $11.1 \pm 1.2$ & $11.2 \pm 1.1$ & $11.0 \pm 1.2$ & $11.1 \pm 1.2$ & 0.096 \\
\hline Serum sodium, mEq/l & $138.5 \pm 2.7$ & $138 \pm 2.7$ & $138 \pm 2.7$ & $138 \pm 2.8$ & $138 \pm 2.7$ & $138 \pm 2.7$ & 0.162 \\
\hline Residual renal urea clearance, $\mathrm{ml} / \mathrm{min}$ & $0.55 \pm 1.33$ & $0.48 \pm 1.17$ & $0.59 \pm 1.34$ & $0.59 \pm 1.36$ & $0.61 \pm 1.82$ & $0.54 \pm 1.36$ & 0.441 \\
\hline SBP change, mm Hg/month & $0.31 \pm 1.83$ & $1.28 \pm 1.79$ & $0.85 \pm 1.56$ & $0.37 \pm 1.68$ & $-0.34 \pm 1.78$ & $-1.46 \pm 2.02$ & $<0.001$ \\
\hline
\end{tabular}

b Stratified per SBP slope quartiles $(\mathrm{n}=3,446)$

\begin{tabular}{|c|c|c|c|c|c|}
\hline & \multicolumn{4}{|l|}{ Slope quartile } & \multirow[t]{2}{*}{$\mathrm{p}$ value } \\
\hline & Q1 ( $\mathrm{n}=862)$ & $\mathrm{Q} 2(\mathrm{n}=861)$ & Q3 $(n=861)$ & $\mathrm{Q} 4(\mathrm{n}=862)$ & \\
\hline \multicolumn{6}{|l|}{ Age, years } \\
\hline Mean $\pm \mathrm{SD}$ & $61.7 \pm 15.4$ & $60.4 \pm 15.3$ & $61.4 \pm 15.3$ & $62.3 \pm 14.3$ & 0.061 \\
\hline Median & 63.0 & 61.3 & 62.2 & 62.9 & \\
\hline Range & $20.8-96.5$ & $18.4-92.8$ & $19.2-97.6$ & $21.3-95.9$ & \\
\hline Male & $497(57.7)$ & $504(58.5)$ & $512(59.5)$ & $487(56.5)$ & 0.637 \\
\hline Race & & & & & 0.422 \\
\hline Black & $382(44.3)$ & $374(43.4)$ & $362(42)$ & $386(44.8)$ & \\
\hline White & $415(48.1)$ & $397(46.1)$ & $421(48.9)$ & $402(46.6)$ & \\
\hline Other & $65(7.5)$ & $90(10.5)$ & $78(9.1)$ & $74(8.6)$ & \\
\hline Body mass index & $27.6 \pm 7.2$ & $27.3 \pm 6.9$ & $27.7 \pm 7.1$ & $27.7 \pm 7.1$ & 0.571 \\
\hline Diabetes & $436(50.6)$ & $420(48.8)$ & $405(47.0)$ & $479(55.6)$ & 0.003 \\
\hline \multicolumn{6}{|l|}{ Laboratory results } \\
\hline Albumin, g/dl & $3.6 \pm 0.4$ & $3.6 \pm 0.4$ & $3.6 \pm 0.4$ & $3.5 \pm 0.5$ & $<0.001$ \\
\hline Creatinine, mg/dl & $7.3 \pm 2.8$ & $6.9 \pm 2.6$ & $6.8 \pm 2.6$ & $7.0 \pm 2.6$ & 0.925 \\
\hline Hemoglobin, g/dl & $11.3 \pm 1.2$ & $11.2 \pm 1.1$ & $11.1 \pm 1.2$ & $11.0 \pm 1.1$ & $<0.001$ \\
\hline Serum sodium, mEq/l & $138.4 \pm 2.6$ & $138.3 \pm 2.7$ & $138.5 \pm 2.8$ & $138.5 \pm 2.8$ & 0.060 \\
\hline Residual renal urea clearance, $\mathrm{ml} / \mathrm{min}$ & $0.50 \pm 1.20$ & $0.58 \pm 1.40$ & $0.52 \pm 1.61$ & $0.70 \pm 1.51$ & 0.902 \\
\hline $\mathrm{SBP}, \mathrm{mm} \mathrm{Hg}$ & $159.5 \pm 20.0$ & $147.6 \pm 19.0$ & $144.8 \pm 18.5$ & $140.9 \pm 17.4$ & $<0.001$ \\
\hline
\end{tabular}

Figures in parentheses are percentages. 


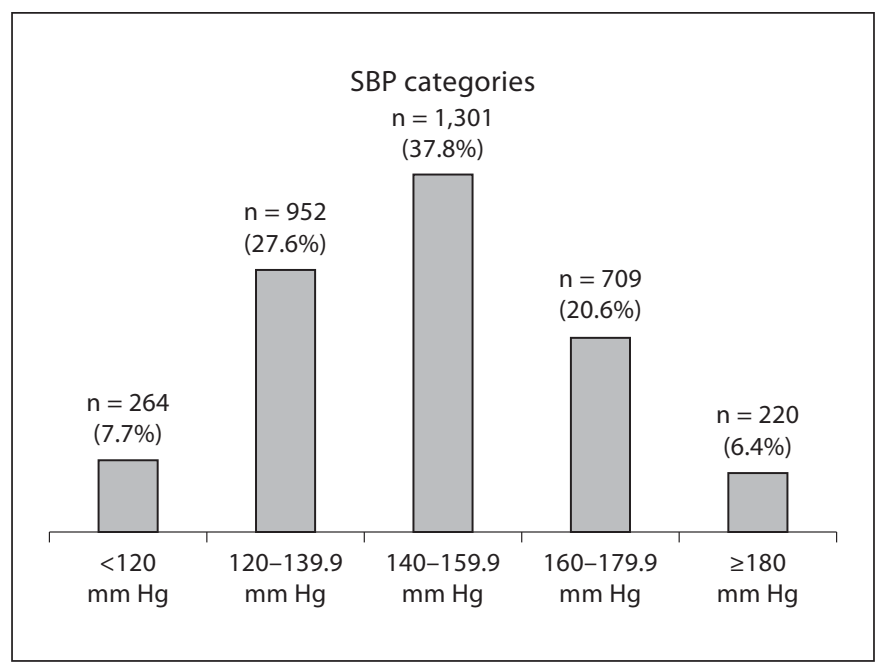

Fig. 2. Distribution of baseline pre-HD SBP (average of weeks $1-3)$.

the most common cause of renal failure (50.5\%). Detailed demographical data stratified by baseline SBP and predialysis SBP slope are shown in table 1a and b, respectively. Total follow-up time was 8,243 patient-years, with a median (25-75 percentile) follow-up time of 1.96 (0.94-3.45) years.

At baseline, more than one third of the patients (37.8\%) had a pre-HD SPB between 140 and $160 \mathrm{~mm} \mathrm{Hg}$ (category 3), and $27.6 \%$ of the patients were in SBP category 2 (120-140 mm Hg; fig. 2).

Between the start of HD (week 0) and week 1, mean pre-HD SBP dropped by $2.8 \mathrm{~mm} \mathrm{Hg}$ [ $95 \%$ confidence interval (CI) -1.4 to -3.1 f from $150.5 \pm 24.1$ to $147.7 \pm 22.9$ $\mathrm{mm} \mathrm{Hg}(\mathrm{p}<0.0001)$. After week 1, SBP increased steadily and reached a plateau at week 12 (fig. 3). The dynamics of SBP differed between the 5 SBP categories: in the lower BP pressure categories (1 and 2), SBP decreased transiently followed by a rise. In contrast, in categories 4 and 5 , SBP rose transiently followed by a decline; SBP in patients in category 3 remained stable throughout the first year (fig. 4).

Pre-HD weight decreased after initiation of HD from $80.7 \pm 22.2 \mathrm{~kg}$ at baseline to $79.4 \pm 21.4 \mathrm{~kg}$ at week 12. After 6 months, pre-HD weight gradually increased and reached $80.7 \mathrm{~kg} \pm 21.8$ at the end of the first year (fig. 3).

The frequency distribution of SBP slopes is shown in fig. 5. Medians (range) of predialysis SBP slope quartiles (in $\mathrm{mm} \mathrm{Hg} /$ week) were Q1: -1.7 (-7.0 to -0.8$)$; Q2: -0.3 (-0.8 to 0.3); Q3: 0.8 (0.3-1.4), and Q4: 2.3 (1.4-9.4).

\section{Survival Analysis}

There were 76 and 244 deaths in the first 6 and 12 months, respectively. First-year Kaplan-Meier survival curves stratified by the SBP group are shown in figure 6 . Mortality in patients with baseline SBP $<120 \mathrm{~mm} \mathrm{Hg}$ was significantly higher compared to patients in other SBP groups ( $p<0.001$ ). Kaplan-Meier analysis of SBP slope quartiles showed that patients in the lowest quartile (Q1) had significantly poorer survival compared to those in the highest quartile (Q4) (fig. 6b).

Results of the Cox models for 6 and 12 months are shown in table 2. After adjustment, baseline SBP $<120$ $\mathrm{mm} \mathrm{Hg}$ was associated with increased mortality at 6 months (hazard ratio 4.80, 95\% CI 1.31-17.52; $\mathrm{p}=0.02$ ) and at 12 months (hazard ratio $1.89,95 \%$ CI 1.03-3.45; $\mathrm{p}=0.04)$. SBP changes in the first 12 weeks were related to survival in Cox analyses. Patients in Q4 had significantly better survival at both 6 and 12 months compared to patients in other slope quartiles $(\mathrm{p}<0.05)$.

\section{Discussion}

A large number of risk factors for mortality have been identified in HD patients including age, race, cardiovascular diseases, HTN, infection, inflammation, diabetic status, hypoalbuminemia and dialysis adequacy [12-17]. In chronic HD patients, BP shows a time-dependent relationship with survival, and an excess mortality risk in patients at the extremes of BP has been noted ('U-shaped relationship') [8-10]. In this study, we tested the hypothesis that absolute SBP and SBP changes in the first 3 months on HD are predictors of outcome. This hypothesis is based on earlier observations that low and decreasing SBP is associated with increased mortality. In a study including 56,338 incident HD patients, Li et al. [10] reported that SBP $<120 \mathrm{~mm} \mathrm{Hg}$, and between 120 to 140 $\mathrm{mm} \mathrm{Hg}$, is associated with a higher mortality risk in the first year of HD. In a recent study, Raimann et al. [11] estimated the slope of SBP change by linear regression using all SBP values in years 1 and 2 in 10,245 HD patients. Patients with an SBP decline had the highest risk of death in both years 1 and 2, irrespective of the absolute SBP at baseline [11]. The main finding of our study is that both low (baseline SBP $<120 \mathrm{~mm} \mathrm{Hg}$ ) and declining SBP in the first weeks on HD are associated with increased mortality after 6 and 12 months, respectively. At 6 months, hazard ratios were 4.8 in patients with a baseline SBP $<120$ $\mathrm{mm} \mathrm{Hg}$, and 2.99 in patients with the steepest SBP decline (Q1). Because of the observational nature of our study, we 


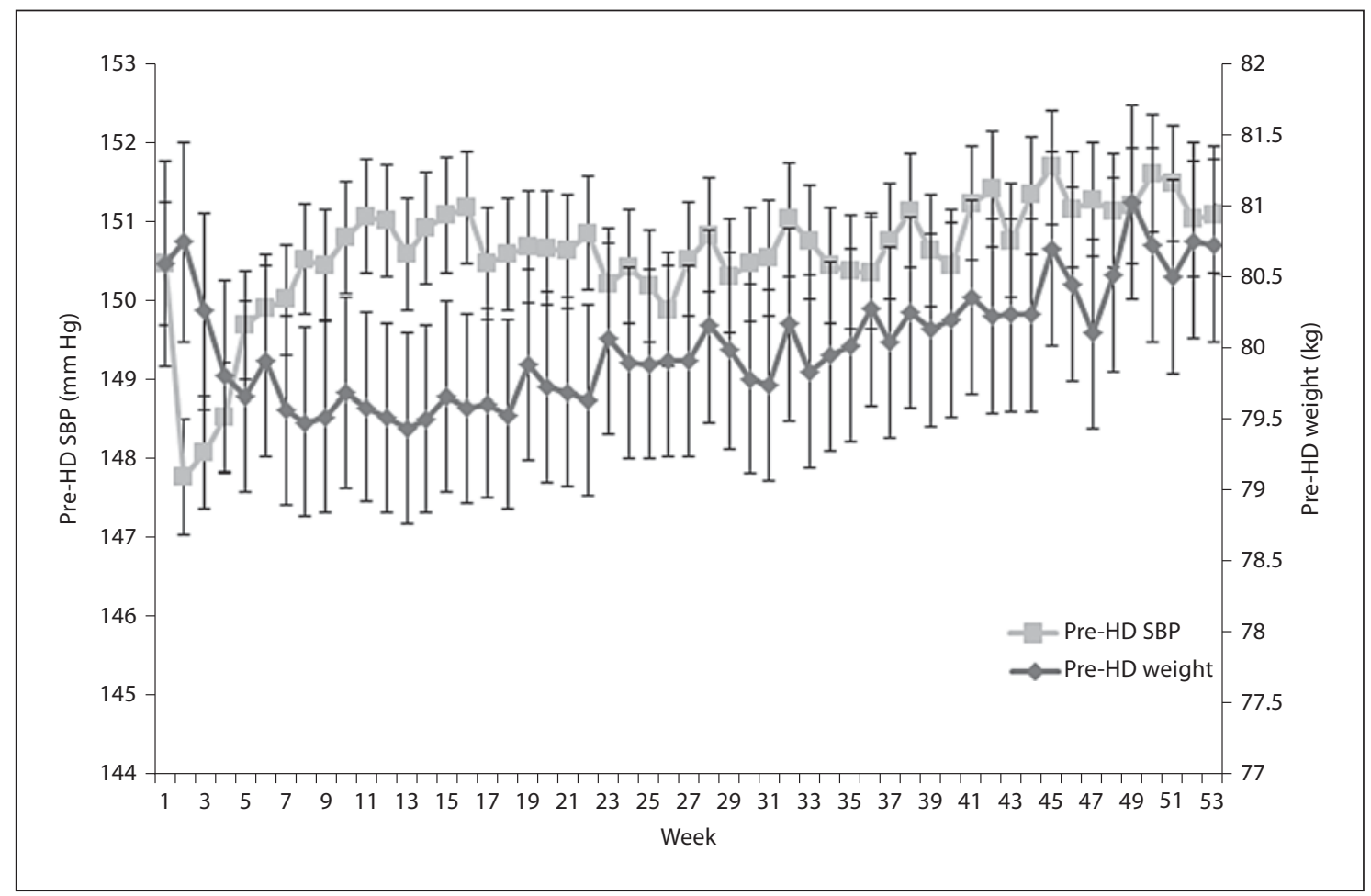

Fig. 3. SBP and pre-HD weight in the first year on $\mathrm{HD}$ (with 95\% CI).

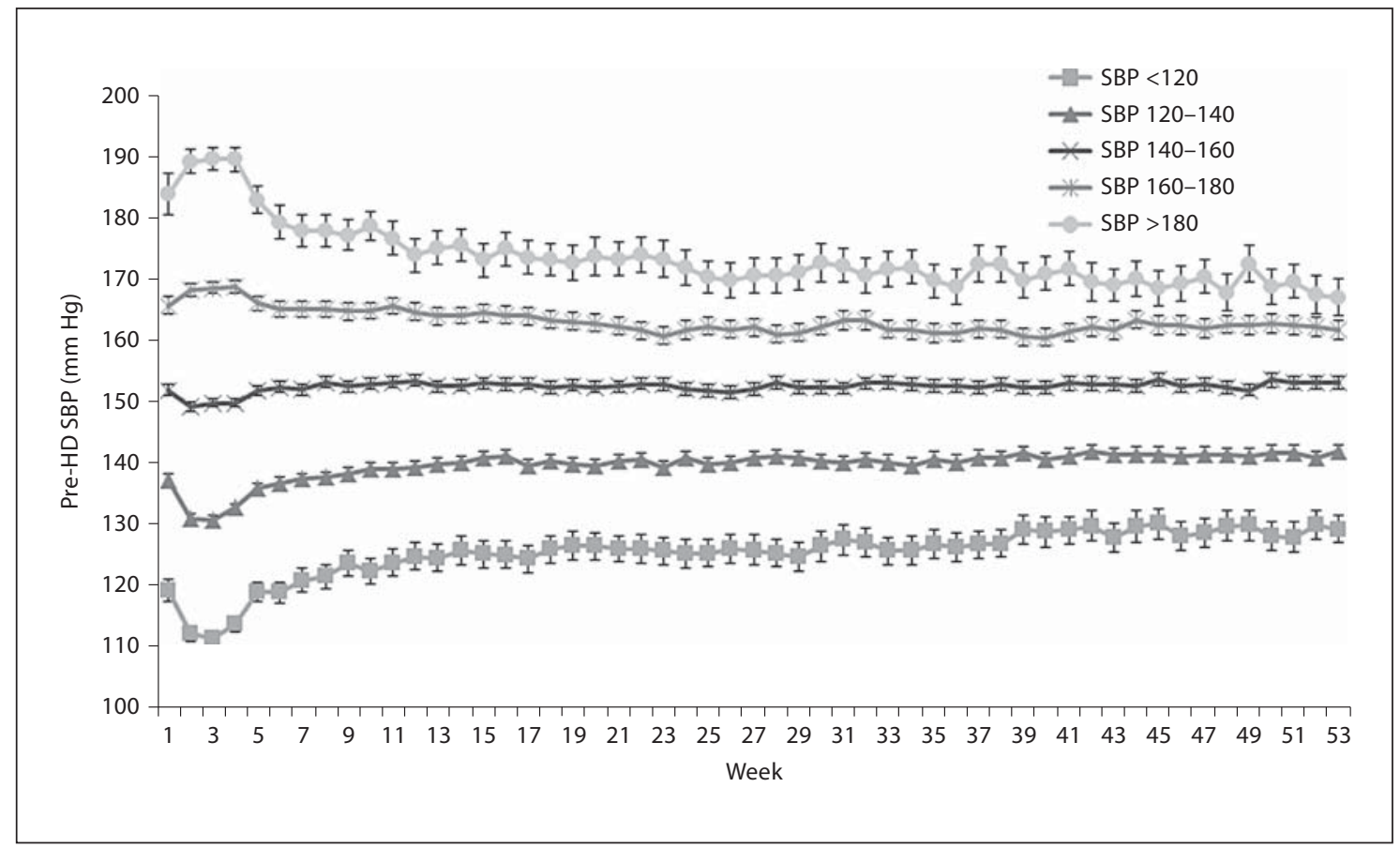

Fig. 4. One-year SBP course in the 5 SBP groups (mean and 95\% CI). 
Table 2. Cox proportional hazard analysis

\begin{tabular}{|c|c|c|c|c|c|c|c|c|c|c|c|c|}
\hline & \multicolumn{6}{|c|}{ 6-month survival } & \multicolumn{6}{|c|}{ 12-month survival } \\
\hline & \multirow[t]{2}{*}{ B } & \multirow[t]{2}{*}{ SE } & \multirow[t]{2}{*}{ Sig. } & \multirow[t]{2}{*}{ HR } & \multicolumn{2}{|c|}{ 95.0\% CI for HR } & \multirow[t]{2}{*}{ B } & \multirow[t]{2}{*}{ SE } & \multirow[t]{2}{*}{ Sig. } & \multirow[t]{2}{*}{ HR } & \multicolumn{2}{|c|}{$95.0 \% \mathrm{CI}$ for $\mathrm{HR}$} \\
\hline & & & & & lower & upper & & & & & lower & upper \\
\hline \multicolumn{13}{|l|}{ SBP group } \\
\hline $\mathrm{SBP}<120 \mathrm{~mm} / \mathrm{Hg}$ & 1.57 & 0.66 & 0.02 & 4.80 & 1.31 & 17.52 & 0.63 & 0.31 & 0.04 & 1.89 & 1.03 & 3.45 \\
\hline SBP $120-139.9 \mathrm{~mm} / \mathrm{Hg}$ & 0.67 & 0.64 & 0.30 & 1.95 & 0.55 & 6.88 & 0.16 & 0.28 & 0.58 & 1.17 & 0.67 & 2.03 \\
\hline SBP $140-159.9 \mathrm{~mm} / \mathrm{Hg}$ & 0.57 & 0.63 & 0.36 & 1.77 & 0.52 & 6.07 & -0.13 & 0.28 & 0.65 & 0.88 & 0.51 & 1.51 \\
\hline SBP $160-179.9 \mathrm{~mm} / \mathrm{Hg}$ & 0.41 & 0.65 & 0.53 & 1.50 & 0.42 & 5.40 & -0.16 & 0.29 & 0.57 & 0.85 & 0.48 & 1.50 \\
\hline \multicolumn{13}{|l|}{ SBP slope quartiles } \\
\hline Q1 & 1.10 & 0.37 & 0.00 & 2.99 & 1.44 & 6.23 & 0.70 & 0.21 & 0.00 & 2.01 & 1.35 & 3.01 \\
\hline Q2 & 0.89 & 0.37 & 0.02 & 2.43 & 1.18 & 5.03 & 0.58 & 0.20 & 0.00 & 1.79 & 1.21 & 2.64 \\
\hline Q3 & 0.64 & 0.38 & 0.09 & 1.90 & 0.90 & 4.00 & 0.57 & 0.20 & 0.00 & 1.76 & 1.19 & 2.60 \\
\hline
\end{tabular}

Adjustments were made for age (in years) at the start of $\mathrm{HD}$, sex, race (white/black/other), diabetic status, cardiovascular comorbidities (congestive heart failure, coronary artery disease, peripheral vascular disease), 12-week averages of laboratory values [serum albumin (g/dl), creatinine (mg/dl), BUN (mg/dl), hemoglobin $(\mathrm{g} / \mathrm{dl})]$, interdialytic weight gain $(\mathrm{kg})$, dialysis adequacy
(eKt/V, as determined by formal urea kinetic modeling), and normalized protein catabolic rate ( $\mathrm{g} / \mathrm{kg}$ body weight/day). SBP $\geq 180$ $\mathrm{mm} \mathrm{Hg}$ and SBP slope quartile Q4 were used as reference categories. $\mathrm{B}=$ Regression coefficient; $\mathrm{SE}=$ standard error; Sig. = Significance; $H R=$ hazard ratio.

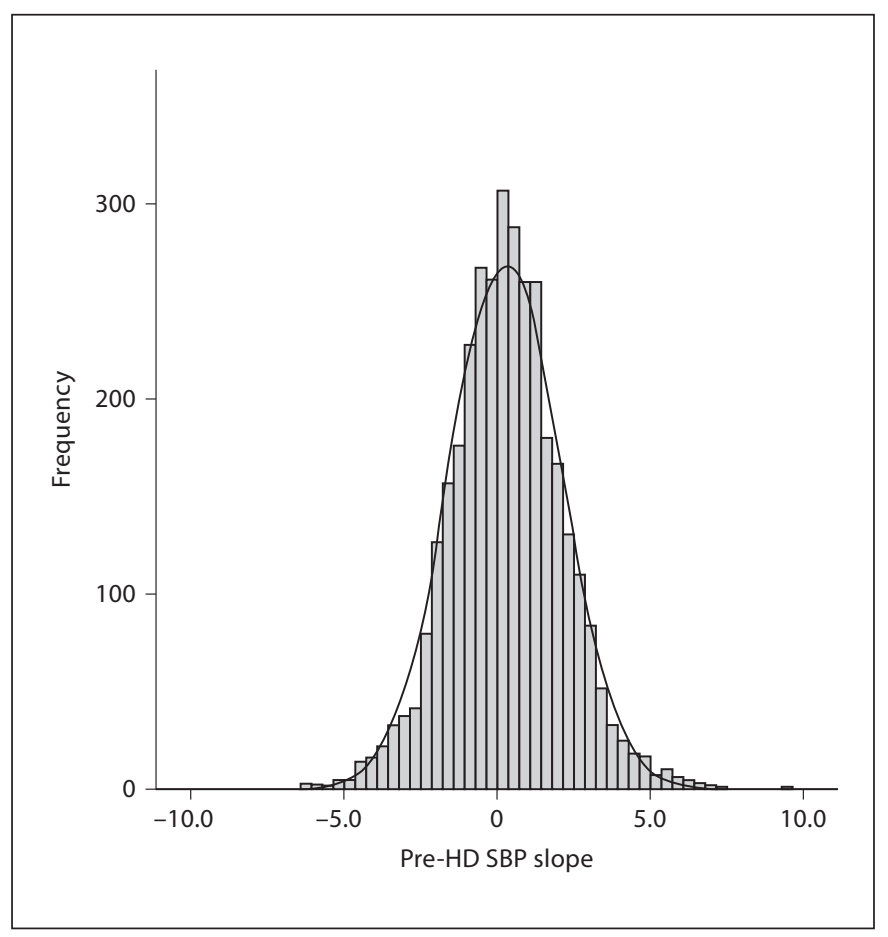

Fig. 5. Distribution of SBP slopes (in $\mathrm{mm} \mathrm{Hg}$ /week) in the first 12 weeks on HD. can only speculate about the underlying mechanisms. When SBP slope quartiles Q1 and Q4 were examined, it is obvious that these groups were heterogeneous in terms of baseline SBP; $47.8 \%$ of patients in SBP slope Q1 had a baseline SBP $\geq 160 \mathrm{~mm} \mathrm{Hg}$ and $48 \%$ of patients in SBP slope Q4 had a baseline SBP $<140 \mathrm{~mm} \mathrm{Hg}$. Although the mean SBP of the study population fluctuated over the first year, it stabilized at an average of about $150 \mathrm{~mm} \mathrm{Hg}$ (fig. 3). The evolution of SBP in the first year on HD stratified by the baseline SBP group is shown in figure 4. Given the observational nature of the study, it cannot be excluded that the declining SBP in patients with high baseline SBP and the rising SBP in patients with a low baseline SBP, respectively, may result to some extent from regression to the mean. However, the retrospective nature of this study prevents quantitative statements about the potential impact of regression to the mean.

The changing relationship of BP with mortality over time has been demonstrated in several studies. Mazzuchi et al. [18] reported that normal or low BP was related with increased mortality during the early years of dialysis, whereas high BP was related with increased mortality in later years. Similar findings were observed by Stidley et al. [9] in 17,000 patients. In their study baseline, pre-HD SBP $<120 \mathrm{~mm} \mathrm{Hg}$ was associated with increased mortality in the first 2 years of $\mathrm{HD}$, whereas SBP $\geq 150 \mathrm{~mm} \mathrm{Hg}$ 


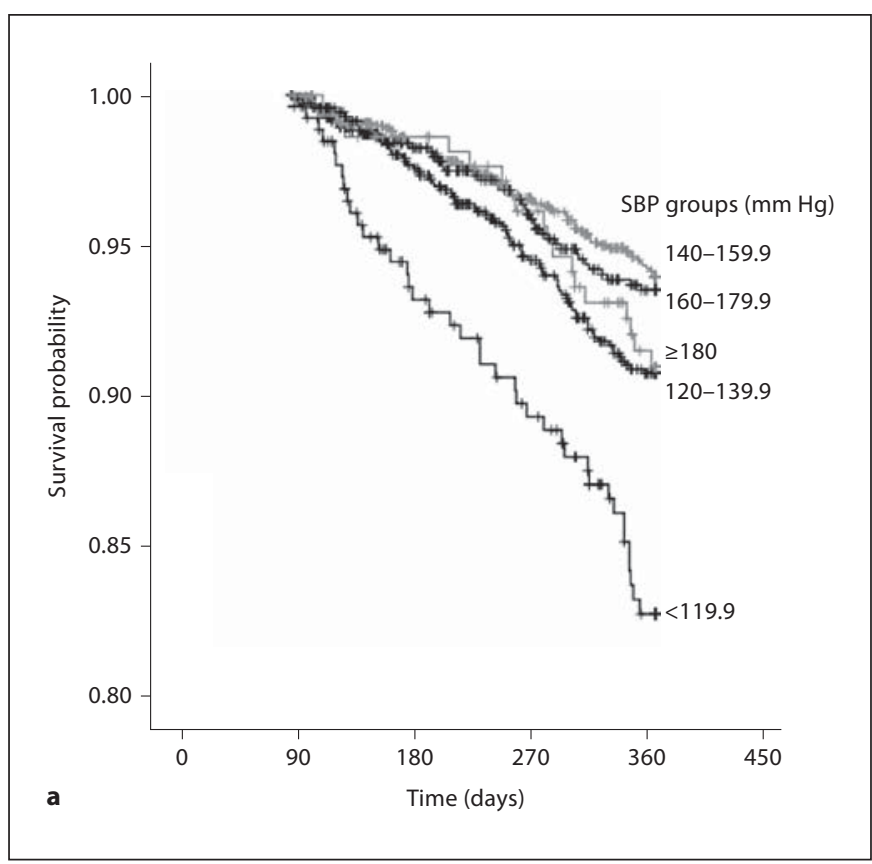

Fig. 6. a Kaplan-Meier curves of 1-year survival stratified by baseline SBP. log-rank test showed significant differences between category 1 (SBP <120 mm Hg) and category 2 (SBP 120-139.9 mm $\mathrm{Hg}$; $\mathrm{p}$ 0.001), category 1 and category 3 (SBP 140-159.9 $\mathrm{mm} \mathrm{Hg}$; $\mathrm{p}<0.001)$, category 1 and category $4(160-179.9 \mathrm{~mm} \mathrm{Hg} ; \mathrm{p}<$

showed its adverse effect on survival after 3 years of $\mathrm{HD}$, indicating that higher $\mathrm{BP}$ is associated with better survival in the early period of HD. Our findings in incident HD patients are in line with these reports, as the mortality risk in the early period (6-12 months) was increased in patients with a baseline SBP $<120 \mathrm{~mm} \mathrm{Hg}$.

In the present study, SBP changes early after initiation of HD were related to mortality in the first year, so that an increase in SBP in the first 3 months after HD initiation was associated with better survival at months 6 and 12 compared to an SBP decrease.

$\mathrm{BP}$ is determined by peripheral resistance and cardiac output and is thus related to cardiac function and volume status. While we have no direct measures of volume status, our data indicate that body weight decreased in the first 3 months most likely because of removal of excess fluid; other potential explanations (e.g. loss in muscle and/or fat mass) are less probable. A reduced fluid overload may improve cardiac function and consequently raise SBP. Hence, the increase in SBP in patients with SBP slope Q4 may be a reflection of improved cardiac function. On the other hand, the high mortality in patients within SBP slope Q1

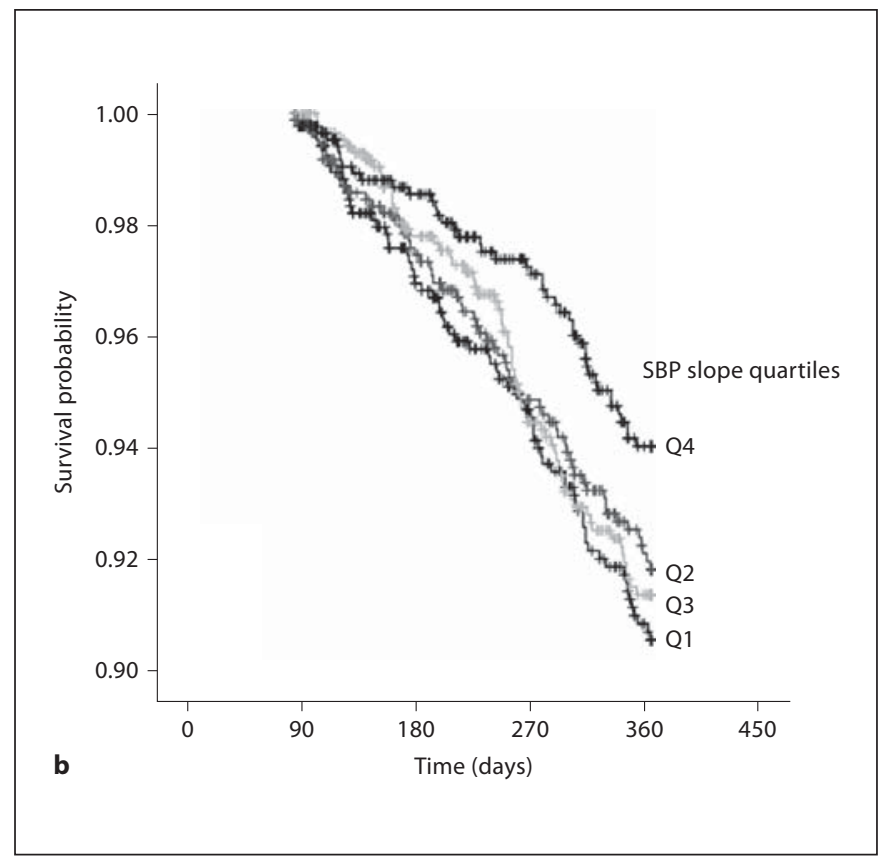

0.001 ), and between category 1 and category 5 (SBP $\geq 180 \mathrm{~mm} \mathrm{Hg}$; $\mathrm{p}=0.009$ ). $\mathbf{b}$ Kaplan-Meier analysis of survival between patients stratified by quartiles of SBP slope. log-rank test showed significant differences between the first and fourth quartile $(p=0.01)$ as well as between the third and fourth quartile $(\mathrm{p}=0.046)$.

may be related to a poor cardiac function at dialysis initiation and a failure to increase cardiac output and SBP. Patients with diastolic dysfunction may have experienced a reduction in cardiac output and SBP because of a decrease in filling pressure. In addition, HD itself may precipitate coronary ischemia, leading to myocardial stunning [19]. In a recent study, HD-induced myocardial stunning was assessed in $70 \mathrm{HD}$ patients by serial intradialytic echocardiography. Myocardial stunning, manifested by the development and subsequent recovery of regional wall motion abnormalities, occurred in around two thirds of patients [20]. In the present study, patients with declining SBP (Q1) may have been affected by myocardial stunning to some degree. Above all, since objective means to determine dry weight (e.g. bioimpedance) were not used, ultrafiltration rates might have been too high or post-HD weight reduction might have been excessive resulting in myocardial hypoperfusion. Higher ultrafiltration volume, which is associated with dialysis-induced cardiac injury and myocardial stunning [20,21], might have resulted in decreased SBP and possibly excess mortality.

Kidney Blood Press Res 2012;35:663-670 
In addition to the observational nature of our study, other limitations are evident. Several options exist to determine BP in HD patients, such as pre- or post-dialysis $\mathrm{BP}$, ambulatory BP measurement, and interdialytic home BP. Reliance upon immediate predialysis and/or postdialysis BP measurements alone to detect $\mathrm{HTN}$ in patients undergoing $\mathrm{HD}$ may be misleading. A single-center cross-sectional study reported that home BP measured by the patients was better than pre-HD BP in predicting left ventricular hypertrophy [22]. Although ambulatory BP measurement and self-measured home $\mathrm{BP}$ are preferable, they are available only in a minority of HD patients and prone to bias by indication. For this reason, pre- and postHD BP was used in this study. In our data system, no indicators of cardiac function (e.g. echocardiography) and dry weight (e.g. bioimpedance) were available. Markers of cardiovascular autonomic nervous functions (e.g. heart rate variability) would have aided data interpretation. Another limitation is the lack of reliable information on antihypertensive drug use in most of the patients. Therefore, we cannot make statements about the relationship between SBP slope and changes in antihypertensive medication.

In conclusion, our data suggest that both baseline SBP and early SBP change are associated with mortality in the first year on HD. Particular attention is warranted in incident HD patients with low SBP and SBP decline in weeks 1-12. Since declining BP may reflect deteriorating cardiac function, echocardiography and early cardiology referral should be considered. Additional prospective studies are necessary to confirm these findings and identify pathophysiological mechanisms.

\section{References}

1 Whaley-Connell AT, Sowers JR, Stevens LA, McFarlane SI, Shlipak MG, Norris KC, et al: CKD in the United States: Kidney Early Evaluation Program (KEEP) and National Health and Nutrition Examination Survey (NHANES) 1999-2004. Am J Kidney Dis 2008;51(suppl 2):S13.

-2 Stamler J, Stamler R, Neaton JD: Blood pressure, systolic and diastolic, and cardiovascular risks. US population data. Arch Intern Med 1993;153:598-615.

-3 Agarwal R, Nissenson AR, Batlle D, Coyne DW, Trout JR, Warnock DG: Prevalence, treatment, and control of hypertension in chronic hemodialysis patients in the United States. Am J Med 2003;115:291-297.

$\checkmark 4$ Kotanko P: Cause and consequences of sympathetic hyperactivity in chronic kidney disease. Blood Purif 2006;24:95-99.

$\checkmark 5$ Levin NW, Kotanko P, Eckardt KU, Kasiske $\mathrm{BL}$, Chazot C, Cheung AK, et al: Blood pressure in chronic kidney disease stage $5 \mathrm{D}$ - report from a Kidney Disease: Improving Global Outcomes controversies conference. Kidney Int 2010;77:273-284.

6 Chobanian AV, Bakris GL, Black HR, Cushman WC, Green LA, Izzo JL Jr, et al: The seventh report of the Joint National Committee on Prevention, Detection, Evaluation, and Treatment of High Blood Pressure: the JNC 7 report. JAMA 2003;289:2560-2572.

$\checkmark 7 \mathrm{~K} / \mathrm{DOQI}$ clinical practice guidelines for cardiovascular disease in dialysis patients. Am J Kidney Dis 2005;45:S1-S153.
8 Zager PG, Nikolic J, Brown RH, Campbell MA, Hunt WC, Peterson D, et al: 'U' curve association of blood pressure and mortality in hemodialysis patients. Medical Directors of Dialysis Clinic, Inc. Kidney Int 1998;54: 561-569.

9 Stidley CA, Hunt WC, Tentori F, Schmidt D, Rohrscheib M, Paine S, et al: Changing relationship of blood pressure with mortality over time among hemodialysis patients. J Am Soc Nephrol 2006;17:513-520.

10 Li Z, Lacson E Jr, Lowrie EG, Ofsthun NJ, Kuhlmann MK, Lazarus JM, et al: The epidemiology of systolic blood pressure and death risk in hemodialysis patients. Am J Kidney Dis 2006;48:606-615.

- 11 Raimann J, Usvyat LA, Thijssen S, Kotanko P, Rogus J, Lacson E Jr, Levin NW: Blood pressure stability in hemodialysis patients confers a survival advantage: results from a large retrospective cohort study. Kidney Int 2012;8:548-558.

12 Collins AJ, Foley RN, Herzog C, Chavers BM, Gilbertson D, Ishani A, et al: Excerpts from the US Renal Data System 2009 Annual Data Report. Am J Kidney Dis 2010;55:S1S420, A6-A7.

$>13$ Mailloux LU, Bellucci AG, Napolitano B, Mossey T, Wilkes BM, Bluestone PA: Survival estimates for 683 patients starting dialysis from 1970 through 1989: identification of risk factors for survival. Clin Nephrol 1994; 42:127-135.

$\nabla_{14}$ Eisenstein EL, Sun JL, Anstrom KJ, Stafford JA, Szczech LA, Muhlbaier LH, et al: Do income level and race influence survival in patients receiving hemodialysis? Am J Med 2009;122:170-180.
-15 Eknoyan G, Beck GJ, Cheung AK, Daugirdas JT, Greene T, Kusek JW, et al: Effect of dialysis dose and membrane flux in maintenance hemodialysis. N Engl J Med 2002;347:20102019.

-16 Goldwasser P, Mittman N, Antignani A, Burrell D, Michel MA, Collier J, et al: Predictors of mortality in hemodialysis patients. J Am Soc Nephrol 1993;3:1613-1622.

17 Myers OB, Adams C, Rohrscheib MR, Servilla KS, Miskulin D, Bedrick EJ, et al: Age, race, diabetes, blood pressure, and mortality among hemodialysis patients. J Am Soc Nephrol 2010;21:1970-1978.

18 Mazzuchi N, Carbonell E, Fernandez-Cean $\mathrm{J}$ : Importance of blood pressure control in hemodialysis patient survival. Kidney Int 2000;58:2147-2154.

19 McIntyre CW: Haemodialysis-induced myocardial stunning in chronic kidney disease - a new aspect of cardiovascular disease. Blood Purif 2010;29:105-110.

20 Burton JO, Jefferies HJ, Selby NM, McIntyre CW: Hemodialysis-induced cardiac injury: determinants and associated outcomes. Clin J Am Soc Nephrol 2009;4:914-920.

21 Jefferies HJ, Virk B, Doss S, Sun S, John SG: Frequent hemodialysis regimens are associated with reduction in dialysis-induced myocardial stunning and systemic inflammation (abstract). J Am Soc Nephrol 2009; 20:439A.

22 Agarwal R, Peixoto AJ, Santos SF, et al: Outof-office blood pressure monitoring in chronic kidney disease. Blood Press Monit 2009;14:2-11. 